\title{
Estratégias individuais e coletivas de gestão dos serviços de higienização e limpeza no setor de hemodiálise de um hospital de referência macrorregional
}

\author{
Individual and collective strategies for the management of hygiene and cleaning services in the \\ hemodialysis sector of a macro-regional reference hospital \\ Estrategias individuales y colectivas para la gestión de los servicios de higiene y limpieza en el \\ sector de la hemodiálisis de un hospital macroregional de referencia
}

\section{Resumo}

Setores de Hemodiálise são locais de alta complexidade de tratamentos e atividades de trabalho, apresentam grande demanda de trabalhadores e pacientes e, consequentemente, elevado grau de risco e de carga de trabalho. Os Serviços de Higienização e Limpeza Hospitalar têm um papel importante para a efetividade dos serviços prestados no setor, bem como para a gestão da saúde e da segurança individual e coletiva. Ao desvelar o real do trabalho a partir das abordagens ergonômica e ergológica, este estudo buscou compreender a atividade das funcionárias dos serviços de higienização e limpeza, a (in)visibilidade dos riscos presentes no setor e a importância do (re)conhecimento das estratégias de regulação diante das variabilidades presentes em um ambiente de trabalho tão complexo. Por meio de um estudo qualitativo descritivo, foi possível levantar a percepção de trabalho dos participantes da pesquisa bem como a importância de sua atuação para a qualidade e segurança no setor. Foi evidenciado que a atuação das trabalhadoras para a gestão local é de extrema importância, mesmo que cotidianamente o trabalho que realizam e os riscos com os quais vivenciam não sejam percebidos pela maior parte dos usuários ali inseridos.

Palavras-chave: Hemodiálise; Riscos; Estratégias.

\begin{abstract}
Hemodialysis sectors are places of high complexity of treatments and work activities, present high demand of workers and patients and, consequently, a high degree of risk and workload. Hospital Hygiene and Cleaning Services play an important role in the effectiveness of the services provided in the sector, as well as for the management of individual and collective health and safety. By undressing the actual work from ergonomic and ergonomic approaches, this study sought to understand the activity of the employees of hygiene and cleaning services, the (in)visibility of the risks present in the sector and the importance of (re)knowledge of regulatory strategies in the face of the variability present in such a complex work environment. Through a descriptive qualitative study, it was possible to raise the perception of work of the research participants as well as the importance of their performance for quality and safety in the sector. It was evidenced that the performance of workers for local management is extremely important, even if daily the work they perform and the risks with which they experience are not perceived by most of the users inserted there. Keywords: Hemodialysis; Risks; Strategies.
\end{abstract}

\section{Resumen}

Los sectores de hemodiálisis son lugares de alta complejidad de tratamientos y actividades laborales, presentan una alta demanda de trabajadores y pacientes y, en consecuencia, un alto grado de riesgo y carga de trabajo. Los Servicios 
de Higiene y Limpieza Hospitalaria desempeñan un papel importante en la eficacia de los servicios prestados en el sector, así como en la gestión de la salud y la seguridad individuales y colectivas. Al desvestir el trabajo real desde enfoques ergonómicos y ergonómicos, este estudio buscó comprender la actividad de los empleados de los servicios de higiene y limpieza, la (in) visibilidad de los riesgos presentes en el sector y la importancia de (re) conocimiento de las estrategias regulatorias frente a la variabilidad presente en un entorno de trabajo tan complejo. A través de un estudio cualitativo descriptivo, fue posible elevar la percepción del trabajo de los participantes en la investigación, así como la importancia de su desempeño para la calidad y la seguridad en el sector. Se evidenció que el desempeño de los trabajadores para la gestión local es extremadamente importante, incluso si diariamente el trabajo que realizan y los riesgos con los que experimentan no son percibidos por la mayoría de los usuarios insertados allí.

Palabras clave: Hemodiálisis; Riesgos; Estrategias.

\section{Introdução}

As constantes transformações no mundo contemporâneo trazem mudanças nos mais diversos cenários, principalmente políticos, econômicos e produtivos. O setor de serviços cresce disparadamente em conjunto com as mais variadas demandas e, juntamente com esse crescimento, emergem diversos desafios no que diz respeito à produção e ao trabalho (Sznelwar et al., 2004). Por definição, o trabalho no setor de serviços é caracterizado como intangível, intransferível, não-estocável e apresenta contato direto entre produtores e consumidores (Rodrigues \& Mendes, 2019).

O trabalho em saúde é economicamente caracterizado por uma prestação de serviços e, dentre as instituições de saúde, os hospitais são marcados pela complexidade e peculiaridade dos serviços prestados (Mendes et al., 2008), "assumindo um papel social, econômico, político e científico, tal como diversas instituições” (Mendes, 2014, p.89). A produção da assistência em ambientes hospitalares é moldada pela complexidade em todos os seus níveis, desde a sua estrutura organizacional, a dinâmica dos processos e a diversidade de insumos e materiais, que acabam revelando a dificuldade de se garantir o funcionamento completo desse sistema (Sznelwar et al., 2004).

Para tanto, o trabalho em saúde também se caracteriza pela prestação de um serviço que se realiza sobre pessoas, com pessoas e para as pessoas, e essas pessoas são coparticipantes no processo de trabalho. Pode ser considerado como uma forma de trabalho abstrata, podendo ser desenvolvido de várias formas, com suas próprias características, baseado nos processos de adaptação constante às relações circunstanciais. É trabalho intelectual, porém, permanece igualmente manual, manifesto atualmente como resultado de ação coletiva e da fragmentação de atos a partir de uma direcionalidade oriunda da autoridade técnica e social imposta pela racionalidade médica (Hennington, 2011).

Não levar em consideração as especificidades do setor de serviços e as atividades realizadas nessas condições acarreta diversas incompatibilidades na realização do trabalho, podendo ser associadas ao adoecimento desses trabalhadores (Sznelwar et al., 2004). Para além disso, Dejours (2008a) coloca a importância de se observar, a partir da proximidade in loco, a fim de buscar a compreensão do trabalho real, partindo de interrogações acerca da lacuna entre o prescrito e o real, o contexto organizacional, o visível e o invisível, os métodos desenvolvidos, os vínculos ali estabelecidos, bem como todas as características das pessoas envolvidas na dinâmica do trabalho.

Compreender o trabalho e a complexidade que o cerca ainda é considerado um desafio para a pesquisa científica. O trabalho real, que é efetivamente realizado diariamente, com todas as suas peculiaridades e processos de tomada de decisão, segue muitas vezes invisível diante de todo o processo de produção. As consequências da realização de uma atividade para a saúde, para a vida da população trabalhadora e para a produção só se tornam acessíveis quando se tornam visíveis (Daniellou, 1996; Dejours, 1993; Wisner, 1993; Guérin et al., 2005).

Contudo, este estudo foi realizado com o objetivo de desvelar os riscos, as variabilidades, as estratégias de regulação, as competências, saberes e valores desenvolvidos individual e coletivamente para a gestão dos riscos no Setor de Hemodiálise de um hospital interiorano, com as funcionárias dos Serviços de Higienização e Limpeza Hospitalar, visando compreender as 
questões relacionadas à (in)visibilidade do trabalho e dos riscos no setor, bem como a importância do agir competente, individual e coletivamente, para a gestão da atividade e dos riscos ali presentes.

\section{Metodologia}

$\mathrm{O}$ presente artigo se desenvolveu por meio de um estudo qualitativo descritivo de corte transversal com fundamentação teórica e metodológica fundamentadas na Ergonomia e na Ergologia, baseando-se nos estudos de Guérin et al., (2005) e Schwartz e Durrive (2010).

As organizações de trabalho esperam que os trabalhadores atinjam objetivos, através de uma série de procedimentos prescritos, e isso é definido por tarefa ou trabalho prescrito. Os detalhes de como os trabalhadores executam as suas tarefas para alcançarem os seus objetivos é definido como atividade ou trabalho real. Diversas são as variabilidades presentes nos processos de trabalho que muitas vezes não podem ser antecipadas. Através da lacuna entre o que é prescrito e o que é efetivamente realizado, que se observa a realidade da atividade do ser humano nos mais diversos meios profissionais (Guérin et al., 2005). Além de dar luz às questões centrais do conjunto teórico ergonômico, a abordagem ergológica oferece sustentabilidade para o aprofundamento em abordagens pluridisciplinares, possibilitando uma abrangente compreensão das complexidades das relações entre trabalho e produção (Schwartz \& Durrive, 2010).

O estudo foi aprovado por dois Comitês de Ética em Pesquisa (proponente e coparticipante), por meio dos Certificados de Aprovação para Apreciação Ética - CAAE 75205517.5.0000.5559 e 75205517.5.3001.5110, respectivamente. Os trabalhadores foram abordados individualmente, no local de trabalho, informados sobre os objetivos e convidados a participar do estudo, e foi entregue para cada participante do estudo o Termo de Consentimento Livre e Esclarecido, assegurando o total conhecimento e voluntariedade dos envolvidos.

As coletas de dados foram realizadas no período de abril de 2019 a janeiro de 2020, onde se iniciou o trabalho de compreensão da organização hospitalar, sobre o setor escolhido, o trabalho prescrito às funcionárias dos Serviços de Higienização e Limpeza e suas principais demandas. Essa etapa foi realizada através de diálogos com as funcionárias objetos do estudo, com os responsáveis pelo setor, por análise documental e aplicação de um questionário semiestruturado com informações sobre aspectos sócio demográficos dos participantes, tais como, idade, sexo, jornada de trabalho, setor de trabalho, tempo de serviço e escolaridade. Após essa etapa, por meio de um estudo com caráter descritivo e exploratório, que aconteceu a partir de várias visitas ao setor (inicialmente semanal, posteriormente quinzenalmente), foi possível acompanhar todo o trabalho das funcionárias, utilizando de observações sistemáticas, transcrições das verbalizações dos trabalhadores envolvidos, auto confrontações e crônicas da atividade. Posteriormente a fase de coletas de dados, foi realizada a ordenação e avaliação dos pontos que mais demonstraram relevância para o estudo.

\section{Resultados e Discussão}

\subsection{Complexidades do Setor de Hemodiálise}

Quando os rins perdem a capacidade de remover resíduos dos processos do metabolismo e as suas outras funções reguladoras, caracteriza-se a insuficiência renal, que acomete milhares de pessoas todos os anos. Os Serviços de Terapia Renal Substitutiva (STRS) são uma alternativa para que essas pessoas possam buscar uma melhoria na qualidade de vida. O tratamento consiste na filtragem e purificação do sangue, visto que os rins passam a não desenvolver bem essa função. Através de um acesso venoso que estabelece um fluxo sanguíneo adequado, o sangue é transportado por meio de um sistema de circulação extracorpórea até um filtro capilar, onde é depurado e depois devolvido para o corpo (Ribeiro et al., 2008; Sesso et al., 2011; Mariotti, 2009). 
Os serviços de diálise são realizados de forma simultânea em inúmeros pacientes, em um mesmo ambiente, favorecendo a disseminação de microrganismos (Rosetti \& Tronchi, 2014). Além disso, são locais susceptíveis à ocorrência de eventos adversos, pois apresentam vários fatores de risco, como: procedimentos invasivos, utilização de equipamentos complexos, pacientes críticos, alta rotatividade de pacientes e administração de medicamentos potencialmente perigosos (Holley, 2006).

O Setor de Hemodiálise foi escolhido para este estudo após visitas iniciais em diversos setores, onde este apresentou maior relevância pela sua alta demanda, rotatividade, procedimentos invasivos e elevada carga de trabalho. O hospital possui 3 salões no Setor de Hemodiálise para realização dos procedimentos, funcionando em 3 turnos, sendo das 07:00 às 11:00 horas, das 12:00 às 16:00 horas e das 17:00 às 21:00 horas. São atendidos pacientes em tratamento de Hemodiálise, Diálise Peritoneal Ambulatorial Contínua e Diálise Peritoneal Automatizada. O hospital oferece serviços de referência para toda a cidade e região, sendo atendidos aproximadamente 33 pacientes por turno num total de três turnos por dia, com aproximadamente 225 pacientes por mês, totalizando em média 2600 sessões.

Os participantes do estudo foram um público inteiramente feminino, composto por 5 funcionárias, com faixa etária variando entre 32 e 48 anos, com tempo de atuação no hospital entre 4 meses a 11 anos, e especificamente no setor de Hemodiálise, de 4 meses a 7 anos. As funcionárias atuam em turnos de 12x36 (doze horas de trabalho por 36 horas de descanso), com o primeiro turno se iniciando às 7:00 e se encerrando às 19:00. Apenas uma funcionária trabalhava meio período de segunda à sexta, iniciando às 7:00 e finalizando às 13:00. Aos domingos não ocorrem sessões de hemodiálise e, a funcionária que trabalha neste dia, auxilia no processo de desinfecção geral do setor, juntamente com as técnicas de enfermagem. Este processo consiste na limpeza e desinfecção de todo o setor da hemodiálise, incluindo máquinas, equipamentos, leitos, chão, paredes, teto e cortinas, com o objetivo de destruir todos os microrganismos patogênicos mediante a aplicação de solução germicida nas superfícies previamente limpas.

Malta e Merhy (2010) apontam que os cuidados com pacientes com doenças crônicas devem se dar de forma integral e isso só se torna possível quando o cuidado é "organizado em rede". Contudo, como sugere Moreira (2015), a qualidade do cuidado em saúde na Terapia Renal Substitutiva se dá pela complexidade das articulações das equipes envolvidas, dos processos de trabalho e das condições de infraestrutura ali presentes. Rosetti e Tronchi (2014) ressaltam ainda que, a assistência prestada na Hemodiálise é complexa, assim como todas as atividades ali presentes, evidenciadas pelas suas especificidades e que a prática assistencial segura só se dá pela formação de uma estrutura com profissionais capacitados.

\subsection{Serviços de Higienização e Limpeza Hospitalar: os riscos presentes na atividade}

De acordo com Sznelwar et al., (2004), faz-se necessário levar em consideração não só os trabalhadores que têm contato direto na assistência ao paciente, mas todos os processos de produção de serviços hospitalares, como aqueles que garantem o funcionamento dos serviços por meio de atividades que provêm insumos necessários à produção. Muitas vezes essas atividades não são conhecidas, visto que não atuam diretamente com os cuidados clínicos, como é a situação dos serviços de higienização e limpeza, essenciais para o funcionamento da organização hospitalar, principalmente pela realização de ações não previstas, além daquelas realizadas cotidianamente, mas que auxiliam direta ou indiretamente nos cuidados.

Os serviços de Higienização e Limpeza Hospitalar consistem em realizar procedimentos que visam alcançar um ambiente sem sujidades, livre de microrganismos infecciosos e abrange todos os cuidados relacionados aos artigos e áreas hospitalares. Os tipos de descontaminação dependem de vários fatores, como o tipo de superfície, a matéria orgânica ali presente, o local e a finalidade. Esses procedimentos podem ser classificados em três grupos: a limpeza (remoção de sujidades e detritos para manter em estado de asseio os artigos e áreas, não devendo ser realizada a seco, visto que podem espalhar poeira e qualquer microrganismo pelo ar, então, preferencialmente são realizadas por meio da escovação com água e sabão, fricção ou 
passar pano), a desinfecção (limpeza dos agentes infecciosos utilizando de meios físicos e químicos) e a esterilização (destruição total de todos os microrganismos, através de agentes físicos ou químicos, sendo realizada especificamente a artigos e locais críticos e semicríticos) (Brasil, 2012).

Descrevendo ainda os processos dos serviços de Higienização e Limpeza, outros critérios devem ser levados em consideração, como as áreas hospitalares, caracterizadas como críticas (procedimentos invasivos ou agentes de alto risco), semicríticas (patologias infecciosas de baixa transmissibilidade ou doenças crônicas) e não-críticas (todas que não são ocupadas por pacientes nem são realizados procedimentos). Além disso, as descontaminações podem ser concorrentes, que são realizadas diariamente em todas as áreas do hospital, imediata, que visa a descontaminação das sujidades e matérias orgânicas sempre que necessário e a descontaminação terminal, realizada em todas as áreas do hospital periodicamente ou conforme protocolo, após alta de pacientes ou cronograma mensal (Brasil, 2012).

Segundo Molinier (1995) e Pitta (1990), o trabalho em um hospital pode ter diversos tipos de constrangimentos, como o elevado esforço físico e posturas inadequadas, insuficiência de equipamentos, layout hospitalar inadequado, desgaste pessoal, diversos riscos de acidentes e contágio, trabalhos em turnos, elevada carga de trabalho, dentre outros. Ainda, segundo Sznelwar et al., (2004). "uma das consequências deste estado de coisas é o número expressivo de afastamentos de trabalhadores em vários setores tanto por problemas físicos quanto decorrentes de sofrimento psíquico" (Sznelwar et al., 2004, p. 47). Neste contexto, foram transcritas algumas verbalizações das funcionárias que retratam situações de riscos percebidas e vivenciadas por elas dentro do setor:

"Teve uma época que tive que me afastar do setor, sentia muitas dores nos braços e nas pernas [...] tinha uma época aqui que não tinha jeito, as técnicas de enfermagem jogavam o resto do soro fisiológico no lixo, ai ficava pesado demais, porque a gente não pode entrar com o carrinho de lixo dentro do salão de hemodiálise né [...] a gente sai tirando os lixos e juntando pra levar pro carrinho."

"Já me acidentei duas vezes com agulha, aqui costuma cair agulha no chão. Fiquei com muito medo de ter alguma coisa, na hora só veio meus filhos na cabeça."

"Minha mente fica cansada por causa da rotina repetitiva, fora o meu corpo."

Tendo em vista a complexidade do setor e os riscos ali presentes, é notória a percepção das funcionárias em relação aos pontos mais específicos que as afetam e como a grande demanda de pacientes e funcionários e limitações do espaço físico podem agravar notoriamente esse contexto. Para que os processos sejam realizados de maneira eficaz e segura e atingindo os resultados esperados, diante das variabilidades e constrangimentos cotidianos, as funcionárias vêm se regulando estrategicamente para manter a eficácia, a qualidade, a saúde e a segurança individual e coletiva.

\subsection{Compreendendo o trabalho real e a (in)visibilidade das funcionárias do Serviços de Higienização e limpeza}

O processo de compreensão do trabalho das funcionárias dos serviços de higienização e limpeza partiu de uma série de observações sistemáticas e diálogos. Inicialmente, quando questionadas sobre as tarefas que tinham que desenvolver no setor, todas descreveram a mesma rotina, apresentada de forma cronológica na Figura 1: 
Figura 1 - Linha do tempo das tarefas das funcionárias dos serviços de limpeza.

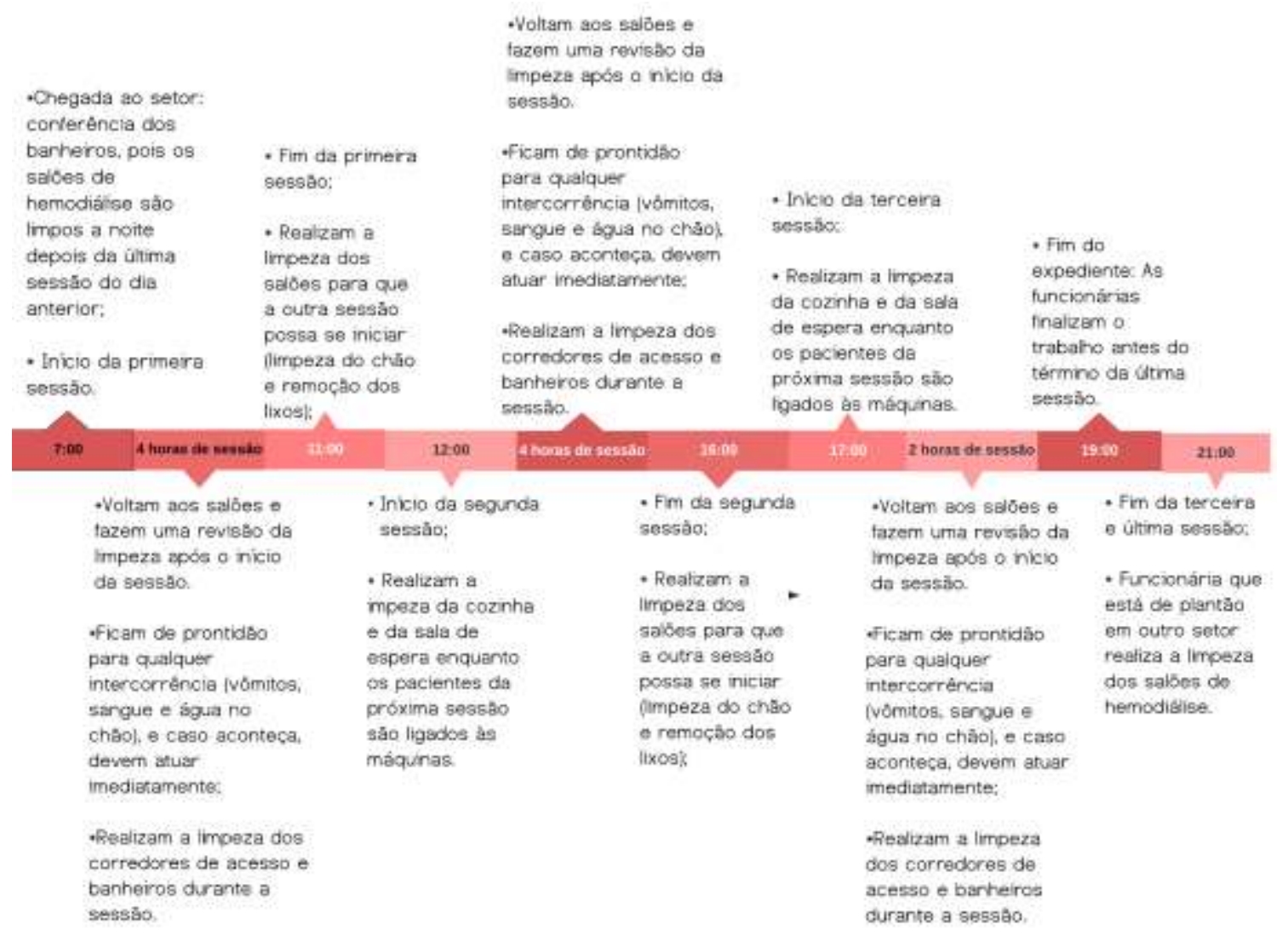

Fonte: Autores (2021).

Como coloca Guérin et al., (2005), as tarefas descritas pelas funcionárias são "um resultado antecipado fixado dentro de condições determinadas" (Guérin et al, 2005, p. 14), ou ainda, "um princípio que impõe um modo de definição do trabalho em relação ao tempo" (Guérin et al., 2005, p. 25). Elas descrevem o que é passado para fazerem e um pouco daquilo que esperam que elas façam, porém, existe uma lacuna entre aquilo que é prescrito e o que realmente acontece.

Todo o conjunto de normas e prescrições muitas vezes não são suficientes para suprir as variabilidades existentes no trabalho e, o que se faz e como é feito passa despercebido, mas é de extrema importância para a construção da saúde e da segurança individual e coletiva no trabalho (Mendes \& Cunha, 2018). Schwartz (1996), descreve como o local de trabalho pode ser profundamente complexo, onde se envolve a atividade humana, as condições ali pré-estabelecidas e os resultados obtidos. E ainda, levando em consideração a abordagem ergológica, a atividade é algo singular, um confronto entre normas e renormalizações, e que é incapaz de ser separada dos valores e traduções humanas de ser, pensar e agir (Schwartz, 2013).

Durante o estudo, foi possível compreender essa lacuna entre o que devia ser executado e como era executado de fato. Trabalhar em um local de tanta complexidade não se trata somente em executar aquilo que é prescrito, mas gerir cada detalhe dentro do seu processo de trabalho:

“A gente tem que fazer a revisão né, depois do início de cada sessão. Eu volto lá mais de uma vez, uma vez não é suficiente, então eu volto secando tudo que vejo, tiro o lixo mais de uma vez [...] imagina acontece alguma coisa de alguém escorregar, machucar ou se contaminar porque não fiz meu serviço direito?”

“Tem que ficar atenta o tempo todo, aqui acontece muita coisa, já sei quando acontece só pela conversa entre as técnicas ou pelo barulho das máquinas, já sei que foi água de alguma máquina que entornou pelo chão ou se é 
sangue que espirrou."

"Eu me sinto muito abafada quando começa a entrar paciente antes que eu termine a limpeza. Não fica do jeito que tem que ficar, porque o tempo é pouco, ai tenho que ficar voltando lá sempre pra dar manutenção. Quando o salão ainda está vazio, consigo limpar tudo sem tanta pressa, não fico tão sobrecarregada [...] tenho que prestar atenção em mim, nos pacientes e nas técnicas. Não sei se você percebeu, mas você viu que tem um jeito até de segurar o rodo? Ele tem que ficar em pé, bem próximo de mim e de costas para a saída, que ai eu consigo controlar ele melhor e não esbarro em nada."

O trabalho é a gestão permanente das variabilidades presentes no meio. A atividade consiste na realização da tarefa prescrita, considerando as possibilidades e impossibilidades impostas pelas variabilidades, é gerir as mais diversas situações de trabalho levando em conta a qualidade, a saúde e a segurança (Guérin et al., 2005; Duraffourg, 1998). Diante de toda a demanda do setor em conjunto com as mais diversas intercorrências, as funcionárias realizam suas atividades buscando formas de atender ao que é demandado da melhor forma possível, com os recursos ali disponibilizados, atuando em conjunto com a segurança e a qualidade dos serviços prestados, compensando os desgastes vivenciados com regulações constantes:

"Menina, você acha que sou boba? Trabalho no setor de limpeza hospitalar tem 9 anos. Não tenho nenhum problema na coluna, eu coloco o balde em cima de alguma lixeira, já que não posso ficar movimentando com o carrinho, aí eu não preciso abaixar."

"Deixo duas sacolas no lixo, aí vou entrar lá, tirar o lixo que está na sacola e já tem outro saco embaixo. Parece que não é nada, mas já agiliza bastante."

Os serviços de limpeza hospitalar apresentam diversos fatores que, muitas vezes, são desconhecidos pela gestão. Existe incompatibilidade entre aquilo que é prescrito e o que é real, estabelecendo-se uma simplificação da dinâmica do trabalho e, consequentemente, adotando-se soluções simplistas para os problemas ali presentes. Trabalhadores da limpeza muitas vezes sentem a ausência da valorização do trabalho, não sendo reconhecidos por outros usuários do hospital (Sznelwar et al.,2004). Trabalhar em um contexto hospitalar se traduz em conviver rotineiramente com diversos fatores produtores de sofrimento, muitas vezes decorrentes da organização do trabalho. Apesar dessa convivência, as funcionárias dos serviços de higienização e limpeza não são reconhecidas socialmente como trabalhadoras da saúde, justamente por não prestar assistência direta ao paciente, implicando em pouca visibilidade no que tange o trabalho que realizam. Como mencionam as funcionárias:

“Gosto de trabalhar aqui, aprendo todos os dias e vejo que tudo que faço tem que estar voltado para a qualidade do atendimento dos pacientes, mesmo que eu não cuide deles diretamente, mesmo que o que a gente faça não seja tão valorizado como o mais importante aqui”.

"Esses horários de troca me cansam muito, muita gente saindo, entrando, enfermeira, paciente, médico, ninguém olha muito pra gente não [...] mas a limpeza não pode parar, porque os próximos que entrarem tem que chegar com tudo limpinho".

"É difícil treinar pessoas para trabalhar aqui, tudo deve ser feito tomando muito cuidado, agilidade e estratégia, tem que ter jeito pra limpar tudo, não é só chegar e limpar como todo mundo pensa[...] são muitos detalhes para ser passado assim, no meio da correria e da responsabilidade desse setor". 
Outro tópico é a questão da rotatividade, em que, mesmo que todos os funcionários conheçam todos os tipos de limpeza a serem realizadas, cada setor apresenta sua especificidade, e as mudanças constantes de um setor para o outro traz uma grande dificuldade de adaptação à dinâmica do local. Além disso, outros fatores como subjetividade da avaliação da qualidade da limpeza, dificuldade de interação entre alguns colegas, número reduzido de funcionários para atender às demandas e outras variabilidades cotidianas (Sznelwar et al.,2004). Durante a pesquisa, ocorreu uma troca de funcionárias por um curto período de tempo, e as mudanças foram notáveis por todos os funcionários do setor. Em conversa com o coordenador da hemodiálise foi possível perceber a dimensão dessa mudança:

"As funcionárias experientes sabem que têm que ficar aqui o tempo todo de prontidão, pois acontecem muitas intercorrências. Se vem uma inexperiente, ela muitas vezes não sabe que tem que ficar de prontidão. Aí ela sai, vai para outro lugar pra fazer seja o que for e não achamos ela, acaba que ficamos na mão quando um sangue cai no chão, quando uma água derrama. As que têm mais experiência não precisa nem chamar. O setor é de alta complexidade, todos os detalhes são importantes e elas os conhecem, elas os gerem de forma que a organização funciona bem. Aqui é importante evitarmos transtornos [...] rotatividade não é boa para nosso setor”.

Ao longo da pesquisa, foi possível compreender que as funcionárias reconhecem a importância do seu trabalho e têm a consciência de toda a carga física e psíquica que as cercam, mesmo que isso muitas vezes não seja reconhecido por uma boa parcela dos usuários dos serviços ali prestados. Além disso, percebeu-se que o coletivo do trabalho tem influência direta no processo de tomada de decisão individual, bem como em melhorias percebidas pelas próprias funcionárias, que mostraram ter total liberdade para passar demandas e possibilidades de melhorias com os integrantes do setor:

"A gente tem essa coisa boa aqui de resolver as coisas entre as pessoas do setor. Não vou ficar ouvindo quem não entende de nada que acontece aqui e vem querer dar pitaco".

“[...] depois que a gente falou que o lixo tava pesado por causa dos soros, o pessoal conversou aqui e agora elas não jogam mais, isso ajudou demais".

"Gosto de passar tudo pra nossa coordenadora, a gente vê as coisas porque tamo aqui todo dia e conhecemos as coisas, a gente sabe como resolver o nosso trabalho, podemos ajudar".

Todas as atividades desenvolvidas em um contexto tão complexo são de extrema importância para o funcionamento do setor e as diversas articulações entre os trabalhadores ali inseridos impactam diretamente na gestão da saúde e da segurança dos trabalhadores e dos usuários do local. Muitas vezes, os riscos ali presentes, bem como todas as formas de regulação da atividade, são imperceptíveis aos olhos da gestão, dos colegas de trabalho e dos próprios usuários do setor, mas os resultados desta lacuna desconhecida pela maioria têm influência direta na qualidade dos serviços ali prestados.

Dar luz aos riscos, variabilidades e fatores que influenciam na atividade de um trabalhador, bem como os processos de micro escolhas e regulações que fazem parte da gestão individual e coletiva dos riscos e do próprio funcionamento das atividades, é de fundamental importância para o estabelecimento de melhorias no processo de gestão local, principalmente no que tange as questões de saúde e segurança dos trabalhadores do setor e dos usuários dos serviços prestados. 


\section{Considerações Finais}

Através da análise in loco, utilizando das ferramentas metodológicas que possibilitam a aproximação com o trabalhador, é possível fazer emergir as mais diversas e minimalistas características do trabalho vivo, da atividade real. Dessa forma, entende-se que é necessário se aprofundar nos fatores que não são visíveis ou óbvios, para assim se estabelecer uma maior compreensão das necessidades de todas as articulações desenvolvidas em um contexto de trabalho, bem como as principais questões influenciam em todo o funcionamento da gestão, das atividades, da individualidade e da coletividade, além de desvelar as estratégias que permitem que os trabalhadores atinjam os objetivos esperados pela organização.

A Análise Ergonômica do Trabalho, em conjunto com as ferramentas da Ergologia, foi de grande relevância para a compreensão do contexto de trabalho analisado, como a atividade real de trabalho, os constrangimentos, variabilidades e as (im)possibilidades de regulação ali presentes. Ouvir os trabalhadores, atores de suas atividades, possibilita a percepção de como as estratégias individuais e coletivas podem desenvolver a construção das melhorias no ambiente de trabalho.

A complexidade de um setor de hemodiálise é adjacente às transformações de processos e pessoas ali inseridas. Uma articulação efetiva entre assistência eficaz e a prevalência da saúde, segurança e a qualidade de todos os envolvidos se torna possível quando as especificidades do contexto e da atividade são identificadas, analisadas, compreendidas e valorizadas, em todas as suas dimensões. Atuar com um trabalho tão essencial para o funcionamento dos cuidados em saúde na Terapia Renal Substitutiva traz muitos significados individuais para as funcionárias, e esses significados estão enraizados na realização de suas atividades e na construção coletiva cotidiana.

\section{Agradecimentos}

O presente estudo foi realizado com o apoio do Grupo de Estudos em Saúde e Segurança no Trabalho (GESSTra) da Universidade Federal de Itajubá - Campus Itabira, que possibilitou a parceria com o hospital estudado e o total suporte para a realização da pesquisa.

\section{Referências}

Brasil. (2012). Segurança do paciente em serviços de saúde: limpeza e desinfecção de superfícies/Agência Nacional de Vigilância Sanitária. https://www20.anvisa.gov.br/

Daniellou, F. (1996). L'ergonomie en quête de ses principes. Octarès, France.

Dejours, C. (2008a). Da psicopatologia à psicodinâmica do trabalho. In: Lancman, S.; Sznelzar, L. I. (Org.). Chistophe Dejours: da psicopatologia à psicodinâmica do trabalho. Fiocruz, Paralelo.

Dejours, C. (1993). Travail, usure mentale, nouvelle édition augmentée. De la psychopathologie à la psychodynamique du travail. Bayard Éditons.

Duraffourg, J. (1998). Um robô, o trabalho e os queijos: algumas reflexões sobre o ponto de vista do trabalho. In: DIEESE (org.). Emprego e desenvolvimento tecnológico: Brasil e contexto internacional. DIEESE.

Guérin, F. et al. (2005). Compreender o trabalho para transformá-lo: a prática da ergonomia. USP, Fundação Vanzolini, Edgard Blücher.

Hennington, E. A. (2011). Entre o criativo e o precário: reflexões sobre constrangimentos e possibilidades do trabalhador da saúde em tempos líquidos. In: C.M. Gomez, J.M.H Machado \& P.G.L. Pena, Saúde do Trabalhador na Sociedade Brasileira Contemporânea. Fiocruz.

Holley, J. L. (2006). A descriptive report of errors and adverse events in chronic hemodialysis units. Nephrol News Issues, 20(12), 57-63. https://pubmed.ncbi.nlm.nih.gov/17125098/

Malta, D. C. \& Merhy, E. E. (2010). O percurso da linha do cuidado sob a perspectiva das doenças crônicas não transmissíveis. Interface - Comunicação, Saúde, Educação, 14(34), 593-606. https://www.scielo.br/scielo.php?script=sci_arttext\&pid=S1414-32832010000300010.

Mariotti M.C. (2009). Qualidade de vida na hemodiálise: impacto de um Programa de Terapia Ocupacional. Universidade Federal do Paraná. http://dspace.c3sl.ufpr.br:8080/dspace/bitstream/1884/21795/1/Mariotti.pdf.

Mendes, D. P. (2014). O agir competente como estratégia de gestão do risco de violência no trabalho: o ponto de vista da atividade humana do trabalho dos técnicos de enfermagem de uma instituição pública psiquiátrica. Tese de Doutoramento em Educação - Universidade Federal de Minas Gerais 
Research, Society and Development, v. 10, n. 5, e15110514665, 2021

(CC BY 4.0) | ISSN 2525-3409 | DOI: http://dx.doi.org/10.33448/rsd-v10i5.14665

Mendes, D. P. \& Cunha, D. M. (2018). La opacidad del trabajo de enfermería y las configuraciones del riesgo. Salud Colectiva, 14(4), 725-742. https://doi.org/10.18294/sc.2018.1349.

Mendes, D. et al. (2008). Um olhar sobre a atividade de trabalho de auxiliares e técnicos de enfermagem de uma instituição psiquiátrica: em busca de transformações. In: XV Congresso Brasileiro de Ergonomia - Bahia.

Molinier, P. (1995). Psychodynamique du Travail et identité sexuelle. Thése de doctorat en Psychologie, Conservatoire National des Arts et Metiers, Paris, França.

Moreira, T. R. (2015). Nível de complexidade da estrutura dos serviços de diálise no Brasil: associação com as condições socioeconômicas do município e autoavaliação de saúde dos pacientes. Programa de Pós-Graduação em Saúde Pública - Universidade Federal de Minas Gerais, Belo Horizonte.

Ribeiro R. C. H. M. at al. (2008). Caracterização e etiologia da insuficiência renal crônica em unidade de nefrologia do interior do Estado de São Paulo. Acta Paul Enferm. 21(esp), 201-11.

Rodrigues, P. L. C.; \& Mendes, D. P. (2019). (Im) possibilidades de regulação no trabalho em profissionais do centro de material esterilizado (CME). Trabalho \& Educação, 28(2), 215-230.

Rosetti, K. A. G, \& Tronchi, D. M. R. (2014). Avaliação da conformidade da prática assistencial de manutenção do cateter temporário duplo lúmen para hemodiálise. Revista Latino-Americana de Enfermagem, 22(1), 129-135. https://doi.org/10.1590/0104-1169.2959.2378.

Schwartz, Y.; \& Durrive, L. (2010). Trabalho e Ergologia: conversas sobre atividade humana. EdUFF.

Schwartz Y. (2013). As linhas de desenvolvimento específicas da abordagem ergológica. Universidade Federal de Minas Gerais.

Schwartz Y. (1996). Ergonomie, philosophie et exterritorialité. En: Daniellou F, (org.). L'ergonomie en quête de ses principes: débats épistémologiques. Toulouse: Octarès Éditions.

Sesso R. C. C. et al. (2010). Relatório do Censo Brasileiro de Diálise de 2010. Brazilian Journal of Nephrology, 33(4), 442-447.

Sznelwar, L.I. et al. Análise do trabalho e serviço de limpeza hospitalar: contribuições da ergonomia e da psicodinâmica do trabalho. Revista Produção, 14(3), 045-057.https://www.scielo.br/scielo.php?script=sci_arttext\&pid=S0103-65132004000300006.

Pitta, A. (1990). Hospital: Dor e morte como ofício. Hucitec.

Vieira, M. A. M. (2004). Autoconfrontação e análise da atividade. Em: Figueiredo, M. et al. (Orgs.). Labirintos do trabalho: interrogações e olhares sobre o trabalho vivo, DP\&A.

Wisner, A. (1993). A inteligência no trabalho. Textos selecionados de ergonomia. Fundacentro. 